\title{
Resolution of Rabbit Haemorrhagic Disease Virus 2 (RHDV2; GI.2) Outbreak in Singapore
}

\author{
Kelvin Lim ${ }^{1}$, Alwyn Tan ${ }^{1}$, Kelvin Hoํ․ Wendy Sng ${ }^{1}$, Hwee Ping Lim ${ }^{1}$, Cathy Chan ${ }^{2}$, Toh \\ $\mathrm{Xinyu}^{1}$, Jasmine Ong ${ }^{1}$, and Charlene Fernandez ${ }^{1}$ \\ ${ }^{1}$ National Parks Board \\ ${ }^{2}$ The Animal Doctors Pte Ltd (Singapore) Block 108 Ang Mo Kio Avenue 4 Unit 01-94/96 \\ Singapore 560108
}

June 24, 2021

\begin{abstract}
Rabbit Haemorrhagic Disease (RHD) is a significant viral disease affecting lagomorphs. The first documented cases of RHD in Singapore occurred in adult pet European rabbits in September 2020. Singapore subsequently declared the outbreak resolved in December 2020. Epidemiological investigations ruled out introductions via importation of infected rabbits and contaminated feed. The source could not be definitively determined. However, the findings suggest that the incident involved both interand intra-household transmission and veterinary clinic-household transmission. This incident demonstrated the importance of sustained application of biosecurity measures, epidemiological investigations, and control, including active case finding, expedient vaccine dissemination, and risk communications. It shows that Singapore, an urbanised city-state, without a significant lagomorph population, could still encounter emerging diseases such as rabbit haemorrhagic disease. Given its social impact on rabbit owners, the National Parks Board Singapore and the private veterinarians worked together to communicate and urge the adoption of biosecurity measures and assuage the concerns of rabbit owners.
\end{abstract}

\section{Hosted file}

Manuscript_TED_RHDV2_14062021.docx available at https://authorea.com/users/421746/articles/ 527641-resolution-of-rabbit-haemorrhagic-disease-virus-2-rhdv2-gi-2-outbreak-insingapore 